\title{
A first trimester prediction model for large for gestational age infants: a preliminary study
}

\author{
Francesca Monari ${ }^{1}$, Daniela Menichini ${ }^{2 *}$, Ludovica Spano' Bascio ${ }^{1}$, Giovanni Grandi ${ }^{1}$, Federico Banchelli \\ Isabella Neri ${ }^{1}$, Roberto D'Amico ${ }^{3}$ and Fabio Facchinetti ${ }^{1}$
}

\begin{abstract}
Background: Large for gestational age infants (LGA) have increased risk of adverse short-term perinatal outcomes. This study aims to develop a multivariable prediction model for the risk of giving birth to a LGA baby, by using biochemical, biophysical, anamnestic, and clinical maternal characteristics available at first trimester.

Methods: Prospective study that included all singleton pregnancies attending the first trimester aneuploidy screening at the Obstetric Unit of the University Hospital of Modena, in Northern Italy, between June 2018 and December 2019.

Results: A total of 503 consecutive women were included in the analysis. The final prediction model for LGA, included multiparity $(\mathrm{OR}=2.8,95 \% \mathrm{Cl}: 1.6-4.9, p=0.001)$, pre-pregnancy $\mathrm{BMI}(\mathrm{OR}=1.08,95 \% \mathrm{Cl}: 1.03-1.14, p=0.002)$ and PAPP-A MoM (OR $=1.43,95 \% \mathrm{Cl}: 1.08-1.90, p=0.013)$. The area under the $\mathrm{ROC}$ curve was $70.5 \%$, indicating a satisfactory predictive accuracy. The best predictive cut-off for this score was equal to -1.378 , which corresponds to a $20.1 \%$ probability of having a LGA infant. By using such a cut-off, the risk of LGA can be predicted in our sample with sensitivity of $55.2 \%$ and specificity of $79.0 \%$.
\end{abstract}

Conclusion: At first trimester, a model including multiparity, pre-pregnancy BMI and PAPP-A satisfactorily predicted the risk of giving birth to a LGA infant. This promising tool, once applied early in pregnancy, would identify women deserving targeted interventions.

Trial registration: ClinicalTrials.gov NCT04838431, 09/04/2021.

Keywords: Prediction model, LGA, First trimester, Biochemical markers, Biophysical markers

\section{Introduction}

It is well recognized that large for gestational age infants (LGA), defined as a babies born with a birthweight above the 90th centile for gestational age and gender, have increased risks of adverse short-term perinatal outcomes i.e., induction of labor, instrumental vaginal delivery, caesarean section, shoulder dystocia, and perinatal asphyxia [1-4]. These neonates also face long-term increased risks

\footnotetext{
*Correspondence: daniela.menichini91@gmail.com

${ }^{2}$ International Doctorate School in Clinical and Experimental Medicine, Department of Biomedical, Metabolic and Neural Sciences, University of Modena and Reggio Emilia, Via del Pozzo 71, 41121 Modena, Italy Full list of author information is available at the end of the article
}

of death, hospitalization as well as increased occurrence of obesity, hypertension and type 2 diabetes later in life $[5,6]$.

LGA is usually a result of maternal diabetes, obesity, and an excessive weight gain during pregnancy. However, there are several other factors that interplay with fetal growth as the genetics, intrauterine environment, nutrition, and placental function.

Among others, plasma protein A (PAPP-A), an enzyme produced by the placenta and by several maternal tissues [7] which releases insulin-like growth factor from its carrier protein, have been related with size at birth [8]. Indeed, increased PAPP-A between the 9-12 weeks was 
associated with LGA babies, in normal weight women [9]. Also $\beta$ human chorionic gonadotropin ( $\beta-\mathrm{hCG}$ ), which stimulates trophoblast invasion, [10] has been involved since its concentrations correlated with both placental volume and birthweight $[11,12]$.

Fetal growth seems to be affected by other biochemical factors as placental growth factor (PlGF), an angiogenic molecule also produced by the placenta [13]. Higher PlGF levels are related with a better vascular function, which in turn increases glucose transport leading to higher glucose and nutrients exposure to the offspring. An association of PIGF levels with LGA babies, namely in women with preexisting diabetes, has been reported [14]. Furthermore, abnormal levels of inhibin-A were associated to adverse perinatal outcomes, also impacting on fetal growth [15].

Previous prediction models for LGA did not take into account the above reported factors [12] and have been developed either in obese mothers [16] or in women with gestational diabetes mellitus (GDM) [17, 18]. Although PAPP-A, free $\beta$-hCG, lipid [19] and inflammatory (interleukin-6, IL-6) [20] markers have all been included in those models, it is important to remember that GDM is only a proxy of LGA. Thus, the objective of our prospective study is to develop a multivariable prediction model for the risk of having a LGA infant, by using biochemical, biophysical, anamnestic, and clinical maternal characteristics, all available at first trimester.

\section{Materials and methods}

Singleton pregnancies between June 2018 and December 2019 were included in the study among women attending the first trimester Down syndrome screening at the University Hospital of Modena, in the North of Italy (tertiary Hospital).

The study was approved by the Ethical Committee of the Area Vasta Emilia Nord (AVEN, protocol AOU: 0001395/20) and registered (ClinicalTrials.gov: NCT04838431, 09/04/2021). A written informed consent was obtained. Women were included if crown-rump length ranged $45-80 \mathrm{~mm}$ and no signs of miscarriage were present. Pregnancies with major fetal abnormalities were excluded from the study.

For each subject, blood sample was collected in fasting conditions, then centrifuged, and the serum stored at minus $80^{\circ} \mathrm{C}$, for subsequent biochemical analyses. PAPP-A, PlGF, free $\beta$-hCG and Inibin A have been collected following the indications of the preeclampsia screening proposed by the Fetal Medicine Foundation (FMF) [21] and were measured with the automated DELFIA EXPRESS system (Thermo Fisher Scientific, Perkin Elmer $\left.{ }^{\circledR}\right)$. To evaluate the lipid profile, high density lipoproteins (HDL) and triglycerides (TG) were collected, in addiction to Insulin levels and Interleukin-6 as mediators of glucose tolerance and inflammation, respectively. These biochemical markers were all measured through routine laboratory methods.

\section{Assays performance}

Precision of serum makers and cytokine measurements was determined by calculating the coefficient of variation $(\mathrm{CV})$, at different concentrations. The intra-assay $\mathrm{CV}$ ranged 1.2-1.4 for PAPP-A, 2.0-2.4 for free $\beta$-hCG, 4.12.1 for PIGF and 7.2-2.1 for Inhibin A. The inter-assay $\mathrm{CV}$ ranged 2.1-2.5 for PAPP-A, 1.4-2.6 for free $\beta$-hCG, 1.5-3.0 for PlGF, 2.3-2.0 for Inhibin A and 1.5-5.0 for IL-6.

The Limit of Detection (LOD) for the serum makers and cytokine measurements was as following PAPP$\mathrm{A}<5 \mathrm{mU} / \mathrm{L}$, free $\beta$-hCG $<0.2 \mathrm{ng} / \mathrm{mL}$, PlGF $<1.9 \mathrm{pg} / \mathrm{mL}$, Inhibin $A=5,7 \mathrm{pg} / \mathrm{mL}$ and IL- $6=1.5 \mathrm{pg} / \mathrm{mL}$.

The Limit of Quantitation (LOQ) was $<15 \mathrm{mU} / \mathrm{L}$ for PAPP-A, $<0.3 \mathrm{ng} / \mathrm{mL}$ for free $\beta$-hCG, $3.3 \mathrm{pg} / \mathrm{mL}$ for PlGF, $6.3 \mathrm{pg} / \mathrm{mL}$ for Inhibin A and $5 \mathrm{pg} / \mathrm{mL}$ for IL- 6 .

The mean arterial pressure (MAP) was measured with validated automated devices (Dinamap, BLTV6XX). After the women were seated and allowed to rest for $3-5 \mathrm{~min}$, normal $(22$ to $32 \mathrm{~cm})$ adult cuffs were fitted to their both arms. This was repeated two times with $1 \mathrm{~min}$ break in between. The MAP was calculated with the formula $\mathrm{MAP}=\mathrm{DBP}+1 / 3(\mathrm{SBP}-\mathrm{DBP})[22]$, where DBP represents diastolic blood pressure and SBP, systolic blood pressure. We calculated the final MAP as the average of all four measurements. Uterine artery Doppler studies including pulsatility index were measured through transabdominal ultrasound (Voluson E8 or Voluson E10) examinations. As indicated in FMF, when carrying out Doppler studies, color flow mapping was used to identify each uterine artery along the side of the cervix and uterus at the level of internal os. Pulsed wave Doppler imaging was used with the sampling gate set at $2 \mathrm{~mm}$ to cover the whole vessel, and care was taken to ensure that the angle of insonation was less than $30^{\circ}$. When three to five similar consecutive waveforms had been obtained, PI was measured. The uterine artery PI was calculated by adding the right and left pulsatility index together, divided by two. All ultrasound and Doppler studies were carried out by a physician who had received the appropriate certificate of competence in the 11-13+6 week scans and Doppler study from the FMF [23].

Data on pregnancy outcome were collected from the hospital maternity records or directly from women if delivered elsewhere.

Data on pregnancy outcome such as weight gain according to the Institute of Medicine (IOM) recommendations, gestational diabetes, stillbirth, abruptio 
placentae, gestational hypertension and preterm delivery were collected from the hospital maternity records or directly from patients if delivered in another setting. Medical records were reviewed by research associates to obtain anonymized data on mothers and their newborns. Maternal medical history included family history of medical conditions, chronic hypertension, or preexisting diabetes, defined as occurring before pregnancy or within the first trimester. Neonatal outcomes included birthweight, gender, Apgar scores, admission to the neonatal intensive care unit (NICU), length of stay, neonatal morbidities, and mortality. Neonatal anthropometric measures were collected to define newborns as small, appropriate, or large for gestational age (SGA, AGA, LGA, respectively) according to the Italian curves for neonatal growth validated by Bertino E. et al. 2010 [24]. These curves/charts consider not only the birthweight $(\mathrm{BW})$, but also the body length (BL), and head circumference (HC), sex, and birth order. Therefore, neonates whose BW, BL and $\mathrm{HC}$ values fell above the 90th centile were considered LGA. All data were organized in a password protected database.

\section{Statistical analysis}

Quantitative variables were described as the mean \pm standard deviation (SD), whereas qualitative variables were described as the absolute and percentage frequencies. The multivariable prediction model was developed by carrying out the following steps. Firstly, univariate logistic regression models were used to assess the relationship among each relevant independent variable and the risk of having a LGA infant. During this step, several alternative parameterizations were used for quantitative variables, including linear effect; step effect based on median or first / third quartile; step effect based on clinically meaningful values; linear effect on multiples of median (MoM). The metabolic syndrome was defined as the presence of at least three of the following variables: $\mathrm{HDL}<50 \mathrm{mg} / \mathrm{dl}, \quad \mathrm{TG} \geq 150 \mathrm{mg} / \mathrm{dl}, \quad \mathrm{SBP} \geq 130 \mathrm{mmHg}$, $\mathrm{DBP} \geq 85 \mathrm{mmHg}, \mathrm{BMI} \geq 30 \mathrm{~kg} / \mathrm{m} 2$ [25].

The variables that were associated to LGA risk with $p$-value $<0.10$ in the univariate analyses were considered for inclusion in a multivariable logistic model. The final prediction model was determined by a stepwise backward selection procedure in which only independent variables associated to LGA risk with $\mathrm{p}$-value $<0.05$ were retained. Results of logistic models were reported as the Odds Ratio (OR) with 95\% confidence interval and Wald p-value. The overall accuracy of the estimated prediction model was assessed by using the area under the ROC curve with $95 \%$ confidence interval. The formula for the predictive score for LGA was equal to the linear predictor of the final model, in which each independent variable was weighted proportionally to its log OR. The predicted probability of having a LGA infant can be calculated as exp.(score) / [1+ exp.(score)]. Furthermore, we calculated the best score threshold by using the Youden's rule and we reported the associated values for sensitivity and specificity. Statistical analyses were performed by using R 3.6.3 software (The R Foundation for Statistical Computing, Wien).

\section{Results}

Five-hundred and fifteen women agreed to participate in this prospective study. Of them, 2 had spontaneous miscarriage in the second trimester, 2 underwent a therapeutic termination of pregnancy (one for trisomy 21 and one for fetal congenital heart disease detected at ultrasound) while 8 women not delivering at our center were lost to follow-up. Therefore, a total of 503 women were included in the final analysis.

The maternal baseline characteristics were compared between those giving birth to a LGA neonate was (87, $17.3 \%$ ) and the remnants (416) delivering normal weight infants (Table 1).

The two groups were similar for maternal age and education level, while the rate of women with Italian

Table 1 Maternal baseline characteristics

\begin{tabular}{|c|c|c|c|}
\hline & $\begin{array}{l}\text { Non LGA } \\
(N=416)\end{array}$ & $\begin{array}{l}\mathrm{LGA} \\
(N=87)\end{array}$ & $P$ value \\
\hline Maternal age (mean $\pm S D)$ & $32.4 \pm 4.5$ & $33.0 \pm 4.8$ & 0.28 \\
\hline Low education level ( $\leq 8$ years) & $52(12.5)$ & $13(14.9)$ & 0.44 \\
\hline Italian place of origin & $363(87.2)$ & $11(87.3)$ & 0.12 \\
\hline Smoking habits & $27(6.4)$ & $4(4.6)$ & 0.54 \\
\hline BMI classes & & & 0.000 \\
\hline Underweight & $19(4.5)$ & 0 & \\
\hline Normal weight & $266(63.9)$ & $36(41.4)^{*}$ & \\
\hline Overweight & $67(16.1)$ & $29(33.3)$ & \\
\hline Obese & $56(13.5)$ & $19(21.8)$ & \\
\hline Morbidly Obese & $8(1.9)$ & $3(3.5)$ & \\
\hline Nulliparity & $263(63.2)$ & $36(41.4)^{*}$ & 0.0001 \\
\hline Assisted reproductive conception & $15(3.7)$ & $2(2.3)$ & 0.73 \\
\hline Preexisting Diabetes Mellitus & $3(0.7)$ & $3(3.4)^{*}$ & 0.03 \\
\hline Chronic Hypertension & $15(3.5)$ & $3(3.4)$ & 0.97 \\
\hline Metabolic Syndrome ${ }^{a}$ & $21(5.0)$ & $7(8.0)$ & 0.23 \\
\hline \multicolumn{4}{|c|}{ Data are reported as numbers with percentage in brackets } \\
\hline \multicolumn{4}{|c|}{$\begin{array}{l}\text { Metabolic syndrome is defined as the presence of at least } 3 \text { of the } 5 \text { following } \\
\text { variables: }\end{array}$} \\
\hline \multicolumn{4}{|c|}{$-\mathrm{HDL}<50 \mathrm{mg} / \mathrm{dl}$} \\
\hline \multicolumn{4}{|l|}{$-\mathrm{TG}>/=150 \mathrm{mg} / \mathrm{dl}$} \\
\hline \multicolumn{4}{|l|}{$-\mathrm{SBP}>/=130 \mathrm{mmHg}$} \\
\hline \multicolumn{4}{|l|}{$-\mathrm{DBP}>/=85 \mathrm{mmHg}$} \\
\hline$-\mathrm{BMI}>/=30 \mathrm{~kg} / \mathrm{m}^{2}$ & & & \\
\hline
\end{tabular}


place of origin was lower in the LGA group. Moreover, the LGA group included less normal weight while more multiparous women. A higher rate of women with preexisting diabetes mellitus was also found in the LGA group, while metabolic syndrome was similarly represented in the two groups.

Table 2 summarizes the biochemical and biophysical markers for LGA at first trimester enrollment.

Mean arterial pressure $>90 \mathrm{mmHg}$ and the mean pulsatility index of the uterine artery doppler $>90$ th centile, were similar between the two groups as well as plasma insulin, triglycerides, and HDL. Placental and vascular markers as PIGF, inhibin A and IL-6 mean values were comparable while the MoM of PAPP-A significantly differed between groups.

Pregnancy outcomes are reported in Table 3. No significant differences were detected as far as GDM, pregnancy induced hypertension (PIH) or preeclampsia $(\mathrm{PE})$. Interestingly, the number of women who gained more weight than recommended by the Institute of
Medicine (IOM) $(47.1 \%$ vs $20.9 \%)$ was increased in LGA group (Table 3 ).

Table 4 shows the main perinatal outcomes. While a significantly higher percentage of women with a LGA baby underwent induction of labor, the rate of cesarean section and vaginal operative deliveries was similar between the two groups. Neonatal adverse outcomes, as NICU admission, acidosis at birth, defined as an umbilical artery $\mathrm{pH}<7.2$ or Apgar score $<7$ at 5 th minute were comparable.

\section{Early prediction model of LGA risk}

Based on the parameters available in at first trimester, a backward stepwise logistic regression was performed to identify potential predictors of LGA among 14 relevant independent variables (age, parity, Italian place of origin, pre-pregnancy $\mathrm{BMI}$, preexisting diabetes mellitus, HDL, TG, insulin, PAPP-A, PIGF, IL-6, inhibin A, fetal cardiac frequency and metabolic syndrome). The results of both univariate and multivariable analyses

Table 2 Biochemical and biophysical markers under evaluation

\begin{tabular}{|c|c|c|c|}
\hline & $\begin{array}{l}\text { Non LGA } \\
(N=416)\end{array}$ & $\begin{array}{l}\text { LGA } \\
(\mathrm{N}=87)\end{array}$ & P value \\
\hline $\mathrm{MAP}>90 \mathrm{mmHg}$ & $116(27.1)$ & $32(36.8)$ & 0.06 \\
\hline Uterine Doppler PI > 90th centile & $44(10.3)$ & $7(8.0)$ & 0.51 \\
\hline Insulin $(\mu \mathrm{UI} / \mathrm{mL})$ & $11.7 \pm 1.47$ & $15.0 \pm 4.35$ & 0.09 \\
\hline Triglycerides (mg/dL) & $107.32 \pm 4.21$ & $116.00 \pm 9.94$ & 0.09 \\
\hline HDL (mg/dL) & $64.38 \pm 1.1$ & $62.48 \pm 2.5$ & 0.16 \\
\hline Inhibin A (pg/mL) & $322.13 \pm 16.6$ & $342.92 \pm 46.8$ & 0.33 \\
\hline Interleukin-6 (pg/mL) & $1151.05 \pm 191.6$ & $986.18 \pm 391.7$ & 0.47 \\
\hline PAPP-A (MoM) & $1.40 \pm 0.75$ & $1.53 \pm 0.86^{*}$ & 0.04 \\
\hline free $\beta$-hCG (MoM) & $1.12 \pm 0.60$ & $1.01 \pm 0.58$ & 0.36 \\
\hline PIGF (MoM) & $1.23 \pm 0.50$ & $1.28 \pm 0.55$ & 0.11 \\
\hline Fetal cardiac frequency $>162 \mathrm{bpm}$ & $191(44.6)$ & $31(35.6)$ & 0.10 \\
\hline
\end{tabular}

Mean values $\pm S D$ and numbers with percentage in brackets are reported

* $p$ value $<0.05$

MAP: mean arterial pressure; MoM: Multiple of the median

Table 3 Pregnancy Outcomes

\begin{tabular}{llll}
\hline & $\begin{array}{l}\text { Non LGA } \\
(\mathbf{N = 4 1 6 )}\end{array}$ & \multicolumn{1}{c}{$\begin{array}{l}\text { LGA value } \\
(\mathbf{N}=\mathbf{8 7})\end{array}$} \\
\hline $\begin{array}{l}\text { GDM } \\
\quad \text { Insulin treatment }\end{array}$ & & $12(13.7 \%)$ \\
Pregnancy-induced Hypertension & $46(10.7 \%)$ & $7(8.0 \%)$ \\
Pre-eclampsia & $11(2.6 \%)$ & $4(4.6 \%)$ & 0.15 \\
Weight gain above IOM recommendations & $23(5.3 \%)$ & $1(1.1 \%)$ & 0.73 \\
Abruptio Placentae & $6(1.4 \%)$ & $41(47.1 \%)$ & 0.83 \\
Fetal Growth Restriction & $87(20.9 \%)$ & $1(1.1 \%)$ & $\mathbf{0 . 0 0 0 0}$ \\
\hline
\end{tabular}


Table 4 Perinatal Outcomes

\begin{tabular}{llll}
\hline & $\begin{array}{l}\text { Non LGA } \\
(\mathbf{N = 4 2 8})\end{array}$ & $\begin{array}{l}\text { LGA } \\
(\mathbf{N}=\mathbf{8 7})\end{array}$ & P value \\
\hline $\begin{array}{l}\text { Mode of Labour } \\
\text { Spontaneous }\end{array}$ & $303(70.8 \%)$ & $52(59.7 \%)^{*}$ & $\mathbf{0 . 0 1}$ \\
$\begin{array}{l}\text { Induced } \\
\text { Delivery }\end{array}$ & $101(23.6 \%)$ & $35(40.2 \%)^{*}$ & \\
$\quad$ Vaginal & $302(70.6 \%)$ & $61(70.1 \%)$ & 0.10 \\
$\quad$ Vaginal Operative & $28(6.5 \%)$ & $3(3.4 \%)$ & \\
$\quad$ Cesarean Section & $98(22.9 \%)$ & $23(26.4 \%)$ & \\
Male gender & $214(50.0 \%)$ & $49(56.3 \%)$ & 0.14 \\
NICU admission & $14(3.3 \%)$ & $1(1.1 \%)$ & 0.14 \\
Umbilical a. $\mathbf{p H}<\mathbf{7 . 2}$ & $23(5.4 \%)$ & $6(3.4 \%)$ & 0.43 \\
5th min. Apgar $<\mathbf{7}$ & $6(1.4 \%)$ & $1(1.1 \%)$ & 0.89 \\
\hline
\end{tabular}

* $p$ value $<0.05$

were reported in Table 5. At univariate analysis LGA babies were associated with multiparity $(\mathrm{OR}=2.41$, 95\% CI 1.51-3.86, $p=0.001)$, pre-pregnancy BMI $(\mathrm{OR}=1.08,95 \% \mathrm{CI} 1.04-1.12, \mathrm{p}=0.001)$, pre-existing diabetes $(\mathrm{OR}=5.04,95 \% \mathrm{CI} 1.00-25.38, p=0.050)$ and PAPP-A MoM (OR $=1.30,95 \%$ CI 1.00-1.70, $p=0.051)$.

The final prediction model for LGA at multivariable analysis included the following independent variables: multiparity $(\mathrm{OR}=2.8,95 \% \mathrm{CI}=1.6-4.9, \mathrm{p}=0.001)$, pre-pregnancy $\mathrm{BMI} \quad(\mathrm{OR}=1.08,95 \% \mathrm{CI} \quad 1.03-1.14$, $p=0.002)$ and PAPP-A MoM (OR $=1.43,95 \%$ CI $1.08-$ $1.90, p=0.013$ ) (Table 5).

There was no significant effect modification on the risk of LGA among the three variables that were selected for our final predictive model (all, $p>0.05$ ).

The area under the ROC curve was $70.5 \%$, indicating a moderate predictive accuracy (Fig. 1).

The prediction score for LGA risk was as follows: Score $=-4.565+1.030 *$ multiparous +0.079 * BMI +0.358 * PAPP-A MoM. The best predictive cut-off for this score was equal to -1.378 , which corresponds to a $20.1 \%$ probability of having a LGA infant. By using such a cut-off, the risk of LGA can be predicted in our sample with sensitivity of $55.2 \%$ and specificity of $79.0 \%$

\section{Discussion}

This prospective study developed a tool for the early pregnancy prediction of LGA infants in a non-selected population. Previous prediction models for LGA and macrosomia have been build-up in larger, although selected populations, i.e. within obese subjects [16] or in women with a diagnosis of GDM $[17,18]$. Moreover, despite several studies developed predictive models of macrosomal fetus through amniotic fluid [26] and ultrasounds [27], they were performed later, at mid pregnancy. Only one study used first-trimester markers for macrosomia reporting the prediction of macrosomia by fetal NT, free $\beta$-hCG and PAPP-A [28]. Other studies, conducted later in pregnancy found that gestational weight gain [18]

Table 5 Development of the prediction model for LGA risk

\begin{tabular}{|c|c|c|c|c|c|c|c|c|}
\hline \multirow[b]{3}{*}{ Maternal Age (+ 1 year) } & \multicolumn{4}{|c|}{$\begin{array}{l}\text { Univariate analyses } \\
(n=503)\end{array}$} & \multicolumn{4}{|c|}{$\begin{array}{l}\text { Multivariable prediction model } \\
(n=434)\end{array}$} \\
\hline & \multirow{2}{*}{$\frac{\text { OR }}{1.03}$} & \multicolumn{2}{|l|}{$95 \% \mathrm{Cl}$} & \multirow{2}{*}{$\begin{array}{l}\mathbf{p} \\
0.283\end{array}$} & \multirow[t]{2}{*}{ OR } & \multirow[t]{2}{*}{$95 \% \mathrm{Cl}$} & & \multirow[t]{2}{*}{$\mathrm{p}$} \\
\hline & & 0.98 & 1.08 & & & & & \\
\hline Multiparity & 2.41 & 1.51 & 3.86 & 0.001 & 2.80 & 1.61 & 4.87 & 0.001 \\
\hline Italian place of origin & 1.17 & 0.61 & 2.45 & 0.065 & & & & \\
\hline Pre-pregnancy BMI $\left(+1 \mathrm{~kg} / \mathrm{m}^{2}\right)$ & 1.08 & 1.04 & 1.12 & 0.001 & 1.08 & 1.03 & 1.14 & 0.002 \\
\hline Pre-existing diabetes & 5.04 & 1.00 & 25.38 & 0.050 & & & & \\
\hline $\mathrm{HDL} \geq 50 \mathrm{mg} / \mathrm{dL}$ & 0.63 & 0.30 & 1.29 & 0.206 & & & & \\
\hline $\mathrm{TG} \geq 150 \mathrm{mg} / \mathrm{dL}$ & 1.76 & 0.96 & 3.23 & 0.068 & & & & \\
\hline Insulin $\geq \mathbf{2 4}(+1 \mu \mathrm{UI} / \mathrm{mL})$ & 1.74 & 0.92 & 3.29 & 0.091 & & & & \\
\hline PAPP-A (+ 1 MoM) & 1.30 & 1.00 & 1.70 & 0.051 & 1.43 & 1.08 & 1.90 & 0.013 \\
\hline $\operatorname{PIGF}(+1 \mathrm{MoM})$ & 1.21 & 0.75 & 1.97 & 0.432 & & & & \\
\hline IL-6 (+ 1 pg/mL) & 1.00 & 1.00 & 1.00 & 0.477 & & & & \\
\hline Inhibin $\mathbf{A}(+1 \mathrm{pg} / \mathrm{mL})$ & 1.00 & 1.00 & 1.00 & 0.338 & & & & \\
\hline $\mathrm{FCF} \geq 162$ & 0.69 & 0.41 & 1.16 & 0.157 & & & & \\
\hline Metabolic Syndrome & 1.70 & 0.70 & 4.12 & 0.244 & & & & \\
\hline
\end{tabular}

The variables that were associated to LGA risk with $\mathrm{p}$-value $<0.10$ in the univariate analyses were considered for inclusion in a multivariable logistic model. The final prediction model was determined by a stepwise backward selection procedure in which only independent variables associated to LGA risk with $p$-value $<0.05$ were retained 

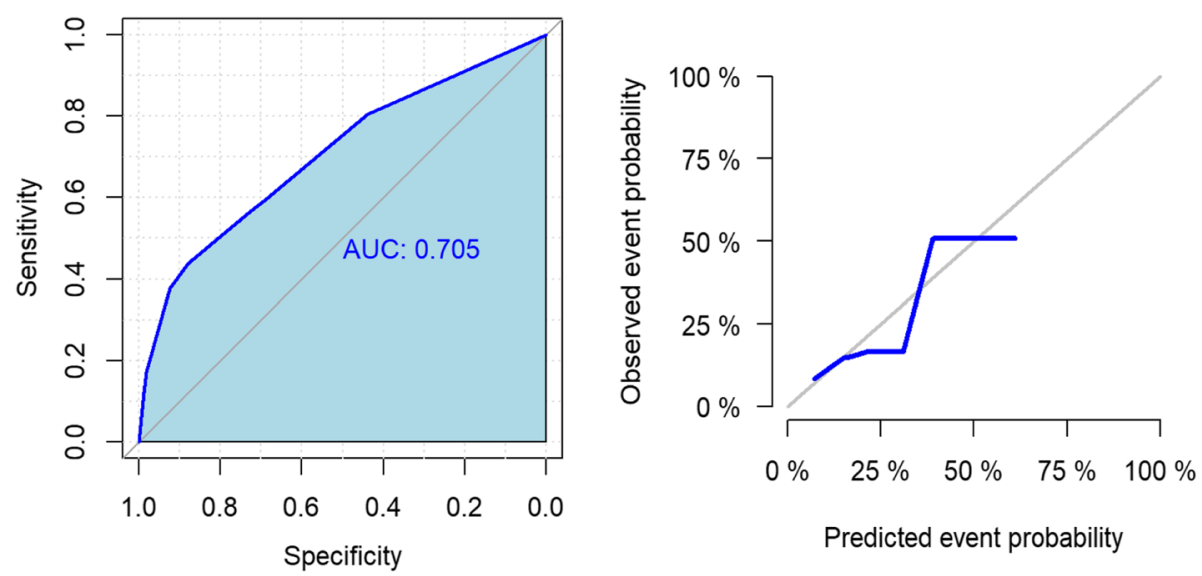

Fig. 1 ROC curve and predicted versus observed event probability plot

and early third-trimester sonographic fetal biometry are predictive of LGA infant at term [17]. Moreover, levels of PAPP-A and free $\beta$-hCG were significantly higher in obese women with an LGA infant compared with obese women with normal-weight infants [16]. On the contrary, in our small series, we included all classes of prepregnancy BMI, women with different ethnicity, parity and with heterogenous obstetric history.

This study thus confirms and enlarges the observation that there is a linear association between MoM of PAPPA levels and LGA, as firstly reported in a cohort of GDM women [29] and later found also in pre-pregnancy obese mothers [16]. This finding is compatible with the observations that glucose levels affect placentation by influencing trophoblast invasion [30]. Indeed, low levels of PAPP-A were reported to be associated with poor early placentation resulting in perinatal complications such as fetal growth restriction, fetal demise, preterm birth, and pre-eclampsia [31].

Moreover, we confirmed that either multiparity and maternal pre-pregnancy BMI are good predictors of increased birthweight and LGA infants [32-34], possibly due to the faster fetal growth transfer in those conditions [35]. On the other hand, it is now assessed that the levels of placental growth factor in maternal blood, as well as the measures of uterine artery pulsatility index, should be excluded among possible markers for LGA [12]. Despite promising, also the other new markers we tested, Inhibin A and Interleukin 6 did not enter in the equation.

The early pregnancy prediction model we obtained is mathematically worth of note, with a satisfactory specificity and an AUC of 0.705 . This tool, in line with the concept of "Inverted Pyramid of Care" [36], adds LGA among those pregnancy complications that could be predicted, hence prevented through timely interventions.
Furthermore, our predictive model has the advantage of using easily and early available variables as they are biophysical (pre-pregnancy BMI), anamnestic (multiparity) or plasma markers (i.e. PAPP-A), unlike those previously mentioned, such as invasive investigations on amniotic fluid [26] or ultrasounds which become accurate only later in pregnancy.

Several studies focused the attention on the excessive gestational weight gain which is a well-recognized factor contributing to LGA [37]. Moreover, also interpregnancy weight increase has been found to be associated with LGA [38]. Implementing an early customized low glycemic index, low fat diet together with the stimulation of physical activity has the potential to reduce the risk of LGA baby in some populations [39, 40]. Unfortunately, quality, timing and adherence to intervention are factors significantly affecting success [39]. In many studies, the window for intervention was too narrow to effectively change women lifestyle and/or it could be too late since the fetal metabolic "programming" was already set [41]. Hence, timing of intervention seems crucial to prevents disorders, and the model we developed helps to start very early in pregnancy.

In summary, multiparity, increased maternal pre-pregnancy BMI and high PAPP-A levels measured at first trimester predict the risk of having a LGA infant, with a good specificity. This helps identify the population which deserves early interventions. We hope this formula will undergo validation in further, larger populations.

\section{Acknowledgements}

We acknowledge the support of the Laboratory "Test" of Modena (Italy), for performing the biochemical analyses and storing serum for subsequent metabolic evaluations. We also thank Perkin Elmer ${ }^{\circledR}$ which offered the measurements of Inhibin A.

Moreover, we are in debt with Dr. Claudia Re, Dr. Francesca Ferrari and Dr. Emma Bertucci who contributed to perform both the Down syndrome screening and uterine artery Doppler studies. 


\section{Authors' contributions}

F.M., D.M. and L.S.B. wrote the main manuscript text and collected the study data. F.B. and R.D. followed the statistical analysis. G.G. collected the data. I.N. and F.F. supervised and conceived the idea of this work. All authors reviewed the manuscript. The author(s) read and approved the final manuscript.

\section{Funding}

There were no funding for this study.

\section{Availability of data and materials}

The datasets used and/or analyzed during the current study are available from the corresponding author on reasonable request.

\section{Declarations}

\section{Ethics approval and consent to participate}

The study was approved by Ethical Committee of the Area Vasta Emilia Nord (AVEN, protocol AOU: 0001395/20) and written informed consent was obtained. All methods were performed in accordance with the Declaration of Helsinki.

\section{Consent for publication}

A consent for anonymized data publication was obtained.

\section{Competing interests}

The authors have no competing interests.

\section{Author details}

'Obstetrics Unit, Mother Infant Department, University Hospital Policlinico of Modena, Modena, Italy. ${ }^{2}$ International Doctorate School in Clinical and Experimental Medicine, Department of Biomedical, Metabolic and Neural Sciences, University of Modena and Reggio Emilia, Via del Pozzo 71, 41121 Modena, Italy. ${ }^{3}$ Department of Diagnostic, Clinical and Public Health Medicine, Statistics Unit, University of Modena and Reggio Emilia, Modena, Italy.

Received: 6 April 2021 Accepted: 10 September 2021

Published online: 24 September 2021

\section{References}

1. Weissmann-Brenner A, Simchen MJ, Zilberberg E, et al. Maternal and neonatal outcomes of large for gestational age pregnancies. Acta Obstet Gynecol Scand. 2012;91(7):844-9. https://doi.org/10.1111/j.1600-0412. 2012.01412.x.

2. Mendez-Figueroa H, Truong V, Pedroza C, Chauhan S. Large for gestational age infants and adverse outcomes among uncomplicated pregnancies at term. Am J Perinatol. 2016;34(07):655-62. https://doi.org/ 10.1055/s-0036-1597325.

3. Jolly MC, Sebire NJ, Harris JP, Regan L, Robinson S. Risk factors for macrosomia and its clinical consequences: a study of 350,311 pregnancies. Eur J Obstet Gynecol Reprod Biol 2003;111(1):9-14. https://doi.org/10. 1016/S0301-2115(03)00154-4.

4. Chavkin U, Wainstock T, Sheiner E, Sergienko R, Walfisch A. Perinatal outcome of pregnancies complicated with extreme birth weights at term. J Matern Neonatal Med. 2019;32(2):198-202. https://doi.org/10.1080/ 14767058.2017 .1376048$.

5. Johnsson IW, Haglund B, Ahlsson F, Gustafsson J. A high birth weight is associated with increased risk of type 2 diabetes and obesity. Pediatr Obes. 2015;10(2):77-83. https://doi.org/10.1111/ijpo.230.

6. Kuciene R, Dulskiene V, Medzioniene J. Associations between high birth weight, being large for gestational age, and high blood pressure among adolescents: a cross-sectional study. Eur J Nutr. 2018;57(1):373-81. https://doi.org/10.1007/s00394-016-1372-0.

7. Boldt HB, Conover CA. Pregnancy-associated plasma protein-a (PAPP-A): a local regulator of IGF bioavailability through cleavage of IGFBPs. Growth Hormon IGF Res. 2007;17(1):10-8. https://doi.org/10.1016/j.ghir.2006.11. 003.
8. Agrogiannis G, Sifakis S, Patsouris E, Konstantinidou O. Insulin-like growth factors in embryonic and fetal growth and skeletal development (review). Mol Med Rep. 2014;10(2):579-84. https://doi.org/10.3892/mmr.2014. 2258.

9. Baer RJ, Lyell DJ, Norton ME, Currier RJ, Jelliffe-Pawlowski LL. First trimester pregnancy-associated plasma protein-a and birth weight. Eur J Obstet Gynecol Reprod Biol. 2016;198:1-6. https://doi.org/10.1016/j.ejogrb.2015. 12.019 .

10. Heidegger $\mathrm{H}$, Jeschke U. Human chorionic gonadotropin (hCG) an endocrine, regulator of gestation and Cancer. Int J Mol Sci. 2018;19(5):1502. https://doi.org/10.3390/ijms19051502.

11. Metzenbauer M, Hafner E, Hoefinger D, et al. Three-dimensional ultrasound measurement of the placental volume in early pregnancy: method and correlation with biochemical placenta parameters. Placenta. 2001;22(6):602-5. https://doi.org/10.1053/plac.2001.0684.

12. Frick AP, Syngelaki A, Zheng M, Poon LC, Nicolaides KH. Prediction of large-for-gestational-age neonates: screening by maternal factors and biomarkers in the three trimesters of pregnancy. Ultrasound Obstet Gynecol. 2016;47(3):332-9. https://doi.org/10.1002/uog.15780.

13. Maynard SE, Min JY, Merchan J, et al. Excess placental soluble fms-like tyrosine kinase 1 (sFlt1) may contribute to endothelial dysfunction hypertension, and proteinuria in preeclampsia. J Clin Invest. 2003;111(5):64958. https://doi.org/10.1172/JCl17189.

14. Kuc S, Wortelboer EJ, Koster MPH, De Valk HW, Schielen PCJI, Visser GHA. Prediction of macrosomia at birth in type-1 and 2 diabetic pregnancies with biomarkers of early placentation. BJOG An Int J Obstet Gynaecol. 2011;118(6):748-54. https://doi.org/10.1111/j.1471-0528.2011.02904.x.

15. Singnoi W, Wanapirak C, Sekararithi R, Tongsong T. A cohort study of the association between maternal serum Inhibin-a and adverse pregnancy outcomes: a population-based study. BMC Pregnancy Childbirth. 2019;19(1):124. https://doi.org/10.1186/s12884-019-2266-y.

16. Åmark H, Westgren M, Persson M. Prediction of large-for-gestationalage infants in pregnancies complicated by obesity: a population-based cohort study. Acta Obstet Gynecol Scand. 2019;98(6):769-76. https://doi. org/10.1111/aogs.13546.

17. Nelson L, Wharton B, Grobman WA. Prediction of large for gestational age birth weights in diabetic mothers based on early third-trimester Sonography. J Ultrasound Med. 2011;30(12):1625-8. https://doi.org/10.7863/jum. 2011.30.12.1625.

18. Boriboonhirunsarn D, Kasempipatchai V. Incidence of large for gestational age infants when gestational diabetes mellitus is diagnosed early and late in pregnancy. J Obstet Gynaecol Res. 2016;42(3):273-8. https://doi. org/10.1111/jog.12914.

19. Sweeting AN, Wong J, Appelblom H, et al. A novel early pregnancy risk prediction model for gestational diabetes mellitus. Fetal Diagn Ther. 2019;45(2):76-84. https://doi.org/10.1159/000486853.

20. Hassiakos D, Eleftheriades M, Papastefanou I, et al. Increased maternal serum Interleukin- 6 concentrations at 11 to 14 weeks of gestation in low risk pregnancies complicated with gestational diabetes mellitus: development of a prediction model. Horm Metab Res. 2015;48(1):35-41. https://doi.org/10.1055/s-0034-1395659.

21. Poon L, Nicolaides K. First-trimester screening for preeclampsia. Prenat Diagn. 2014;34:618-27.

22. DeMers D, Wachs D. Physiology, Mean Arterial Pressure.; 2019.

23. Lai J, Poon LCY, Bakalis S, Chiriac R, Nicolaides KH. Systolic, diastolic and mean arterial pressure at 30-33 weeks in the prediction of preeclampsia. Fetal Diagn Ther. 2013;33(3):173-81. https://doi.org/10.1159/000345950.

24. Bertino E, Spada E, Occhi L, et al. Neonatal anthropometric charts: the Italian neonatal study compared with other European studies. J Pediatr Gastroenterol Nutr. 2010;51(3):353-61. https://doi.org/10.1097/MPG. 0b013e3181da213e.

25. Bloomgarden ZT. American Association of Clinical Endocrinologists (AACE) consensus conference on the insulin resistance syndrome: 25-26 august 2002, Washington, DC. Diabetes Care. 2003;26(3):933-9. https:// doi.org/10.2337/diacare.26.3.933.

26. Boisvert MR, Koski KG, Burns DH, Skinner CD. Early prediction of macrosomia based on an analysis of second trimester amniotic fluid by capillary electrophoresis. Biomark Med. 2012;6(5):655-62. https://doi.org/10.2217/ bmm.12.54.

27. Coomarasamy A, Connock M, Thornton J, Khan KS. Accuracy of ultrasound biometry in the prediction of macrosomia: a systematic 
quantitative review. BJOG An Int J Obstet Gynaecol. 2005;112(11):1461-6. https://doi.org/10.1111/j.1471-0528.2005.00702.x.

28. Poon LCY, Karagiannis G, Stratieva V, Syngelaki A, Nicolaides KH. Firsttrimester prediction of Macrosomia. Fetal Diagn Ther. 2011;29(2):139-47. https://doi.org/10.1159/000318565.

29. Wells G, Bleicher K, Han X, et al. Maternal diabetes, large-for-gestationalage births, and first trimester pregnancy-associated plasma protein-a. J Clin Endocrinol Metab. 2015;100(6):2372-9. https://doi.org/10.1210/jc. 2014-4103.

30. Jensen DM, Korsholm L, Ovesen P, et al. Peri-Conceptional A1C and risk of serious adverse pregnancy outcome in 933 women with type 1 diabetes. Diabetes Care. 2009;32(6):1046-8. https://doi.org/10.2337/dc08-2061.

31. Patil M, Panchanadikar TM, Wagh G. Variation of Papp-a level in the first trimester of pregnancy and its clinical outcome. J Obstet Gynecol India. 2014;64(2):116-9. https://doi.org/10.1007/s13224-013-0481-4.

32. McDonnold M, Mele L, Myatt L, et al. Waist-to-hip ratio versus body mass index as predictor of obesity-related pregnancy outcomes. Am J Perinatol. 2016;33(06):618-24. https://doi.org/10.1055/s-0035-1569986.

33. Stogianni A, Lendahls L, Landin-Olsson M, Thunander M. Obstetric and perinatal outcomes in pregnancies complicated by diabetes, and control pregnancies, in Kronoberg, Sweden. BMC Pregnancy Childbirth. 2019;19(1):159. https://doi.org/10.1186/s12884-019-2269-8.

34. Boubred F, Pauly V, Romain F, Fond G, Boyer L. The role of neighbourhood socioeconomic status in large for gestational age. Farrar D, ed. PLoS One. 2020;15(6):e0233416. https://doi.org/10.1371/journal.pone.0233416

35. Scott A, Moar V, Ounsted M. The relative contribution of different maternal factors in large-for-gestational-age pregnancies. Eur J Obstet Gynecol
Reprod Biol. 1982;13(5):269-77. https://doi.org/10.1016/0028-2243(82) 90049-1.

36. Sonek JD, Kagan KO, Nicolaides KH. Inverted pyramid of care. Clin Lab Med. 2016;36(2):305-17. https://doi.org/10.1016/j.cll.2016.01.009.

37. Institute of Medicine (US) and National Research Council (US) Committee to Reexamine IOM Pregnancy Weight Guidelines. Weight Gain During Pregnancy. (Rasmussen K, Yaktine A, eds.). National Academies Press; 2009. https://doi.org/10.17226/12584

38. Teulings NEWD, Masconi KL, Ozanne SE, Aiken CE, Wood AM. Effect of interpregnancy weight change on perinatal outcomes: systematic review and meta-analysis. BMC Pregnancy Childbirth. 2019;19(1):386. https://doi. org/10.1186/s12884-019-2566-2.

39. Menichini D, Petrella E, Dipace V, Di Monte A, Neri I, Facchinetti F. The impact of an early lifestyle intervention on pregnancy outcomes in a cohort of insulin-resistant overweight and obese women. Nutrients. 2020;12(5). https://doi.org/10.3390/nu12051496

40. Englund-Ögge L, Brantsæter AL, Juodakis J, et al. Associations between maternal dietary patterns and infant birth weight, small and large for gestational age in the Norwegian mother and child cohort study. Eur J Clin Nutr. 2019;73(9):1270-82. https://doi.org/10.1038/s41430-018-0356-y.

41. Barker D. Maternal nutrition, fetal nutrition, and disease in later life. Nutrition. 1997;13:807-13.

\section{Publisher's Note}

Springer Nature remains neutral with regard to jurisdictional claims in published maps and institutional affiliations.
Ready to submit your research? Choose BMC and benefit from:

- fast, convenient online submission

- thorough peer review by experienced researchers in your field

- rapid publication on acceptance

- support for research data, including large and complex data types

- gold Open Access which fosters wider collaboration and increased citations

- maximum visibility for your research: over $100 \mathrm{M}$ website views per year

At BMC, research is always in progress.

Learn more biomedcentral.com/submissions 